\title{
Effect of Thickness on the Structure and Magnetic Properties of FePd Films Grown on Glass Substrate
}

\author{
Zhang Yanli $^{1,2}$, Cheng Gang ${ }^{1,2}$, Xu Xiaozong ${ }^{2}$, Pan Kuang ${ }^{2}$, Li Lin ${ }^{1,2}$, Du Yusong ${ }^{1,2}$, \\ Zhang Xin ${ }^{1,2}, \quad$ Ma Lei ${ }^{1,2}, \quad$ Gu Zhengfei ${ }^{1,2}$ \\ ${ }^{1}$ Guangxi Key Laboratory of Information Materials, Guilin 541004, China; ${ }^{2}$ Guilin University of Electronic Technology, Guilin 541004, China
}

\begin{abstract}
FePd alloy films with different thicknesses have been prepared by DC magnetron sputtering on glass. The effect of thin film thickness on the structural and magnetic properties was investigated by X-ray diffraction (XRD), energy dispersive spectroscope (EDS), and physical property measurement system. The results indicate that the ordering process in the thin FePd alloy film occurs in the thicker ones. In-plane coercivity value first increases rapidly as thickness increases from $d=22.5$ to $d=67.5 \mathrm{~nm}$, and then the value decreases with further increasing film thickness. A peak value of coercivity $3.2 \times 79.6 \mathrm{kA} / \mathrm{m}$ appears at $d=67.5 \mathrm{~nm}$.
\end{abstract}

Key words: FePd film; crystal grain growth; magnetization process

The crystal structure of FePd alloys around the equiatomic composition varies between ordered (L10) and disordered (A1) structures. $\mathrm{L1}_{0}-\mathrm{FePd}$ belongs to the family of ordered intermetallics like FePt and CoPt that exhibit very promising uniaxial magnetic properties ${ }^{[1-8]}$. From writing field and price point of view, FePd film is the most suitable for industrial application, because FePt film coercive force is too large, and the price is expensive. On the other hand, the temperature of ordering transformation for FePd is much lower than that for $\mathrm{FePt}$ as well as $\mathrm{CoPt}^{[9,10]}$. Due to the appropriate magnetocrystalline anisotropy and the lower temperature of ordering transformation, the FePd films are considered as potential materials for application in ultrahigh density magnetic recording media.

In order to increase recording resolution, the magnetic recording layer is required to be as thin as possible. The relationship between the change in thickness of FePd film and phase transformation as well as magnetic properties is not well known. Hence it is important to understand how film thickness affects the structural and magnetic properties of FePd alloys film, which is the purpose of this work.

\section{Experiment}

FePd alloy films were deposited on glass substrates at room temperature by magnetron-controlled sputtering deposition, in an Ar atmosphere, from one target: a disc of Fe with chips of $\mathrm{Pd}$ on its surface, mounted on a gun. The composition was adjusted by the number of Pd chips placed on the Fe disc. The chemical composition of $\mathrm{Fe}_{47} \mathrm{Pd}_{53}$ films were analyzed by energy dispersion spectrum (EDS). The film thickness $d$ was 22.5, 45.0, 67.5, $90.0 \mathrm{~nm}$. After deposition, the samples were annealed in a vacuum of $7 \times 10^{-5} \mathrm{~Pa}$ at $600{ }^{\circ} \mathrm{C}$ for different annealing time. The crystallographic structure of the samples was investigated by a X-ray diffraction (XRD) instrument equipped with a thin film attachment for grazing angle configuration, in order to enhance the surface sensitivity of the technique. The film thickness was determined by step profiler. The out-of-plane and in-plane magnetic properties of the FePd films were measured by a physical property measurement system (PPMS-9).

\section{Results and Discussion}

Foundation item: National Key Basic Research Development Program of China (“973” Program) (2014CB643703); National Natural Science Foundation of China (51261004, 51461012); Natural Science Foundation of Guangxi (2013GXNSFBA019242); the Research Foundation of Guangxi Key Laboratory of Information Materials (131003-Z, 131007-Z)

Corresponding author: Cheng Gang, Ph. D., Professor, School of Material Science and Engineering, Guilin University of Electronic Technology, Guilin 541004, P. R. China, Tel: 0086-773-2291434, E-mail: cheng59@guet.edu.cn 
Fig.1 shows XRD patterns of FePd films with thickness of $90 \mathrm{~nm}$ annealed for different time. The X-ray trace of the as-deposited film reveals a completely disordered fcc phase polycrystalline structure ${ }^{[10]}$. When annealing time reaches $4 \mathrm{~h}$ later, the reflection peak of (110) belonging to fct phase is observed from Fig.1. The structure of the film annealed for $5 \mathrm{~h}$ is mainly composed of fct phase. However, the (200) reflection belonging to fcc phase is still observed in Fig.1. As annealing time increases from $4 \mathrm{~h}$ to $7 \mathrm{~h}$, the intensity of reflections belonging to fct phase increases, and the (200), (220) and (311) reflections of the original fcc phase split to the (200), (002), (220), (202), (311), and (113) reflections of the original fct phase. After annealing at $600{ }^{\circ} \mathrm{C}$ for $7 \mathrm{~h}$ the disordered alloy is transformed into the tetragonal $\mathrm{L}_{0}$ phase (labeled as fct-phase in Fig.1), with sharper and more intense reflections, evidencing a higher quality of the crystal and a much larger grain size. XRD data for the sample annealed for 4 and $5 \mathrm{~h}$ indicate that there exists a nanocomposite alloy phase; namely, fct ordered hard-magnetic precipitated phase coexisting with a fcc disordered soft-magnetic matrix phase. In Fig. 2 the X-ray patterns of FePd films of different thickness annealed for $5 \mathrm{~h}$ are demonstrated. After annealing for the thinnest film with $d=22.5 \mathrm{~nm}$ the only reflections belonging to fcc phase are observed, meaning that the crystalline structure in this sample still remains fcc phase and no transformation has taken place. In case of the thicker samples, with $d=67.5$ and $90 \mathrm{~nm}$, which were annealed at the same conditions the situation is quite different. The appearance of the (110) and the split of (200), (220) and (311) peaks in the X-ray diagrams of these samples have been observed, which indicates the occurrence of the phase transformation from the fcc to fct crystal structure.

The initial magnetization curves measured in the direction parallel to the film plane of FePd films annealed for $5 \mathrm{~h}$ with different thickness can be seen in Fig.3. The saturation state of films is a function of the thickness. The saturated field increases with increased thickness of FePd films. As the film thickness in the process of changes from thin to thick, then the mechanism of the magnetization process also changes from domain nucleation to domain wall pinning type. Fig.4 shows the in-plane and out-of-plane hysteresis loops for FePd alloy films of different thicknesses annealed at $600^{\circ} \mathrm{C}$ for $5 \mathrm{~h}$. It can be seen from Fig.4 that when the film thickness increases, either applied field in-plane or out-of-plane coercivity also will increase. The minimum value of in-plane coercivity is tens oersteds corresponding thickness $d=22.5 \mathrm{~nm}$ while a $\max$ value of in-plane coercivity is about $3.2 \times 79.6 \mathrm{kA} / \mathrm{m}$ with film thickness $d=90 \mathrm{~nm}$ although they have been all heat treated at same conditions. It is suggested that phase transformation from fcc to fct process: the thicker the sample is, the higher the transformation rate and thus the larger the fct volume fraction, just before discussed about the X-ray data and magnetization curves.

Fig.5 shows the dependence of the remanence ratio and coercivity of films on the film thickness. From Fig.5, it can be seen that the remanence ratio increases drastically from $d=22.5$ $\mathrm{nm}$ to $d=45 \mathrm{~nm}$, then nearly linearly decreases from the peak value of $m_{\mathrm{r}}$ to 0.71 with the increase of film thickness.

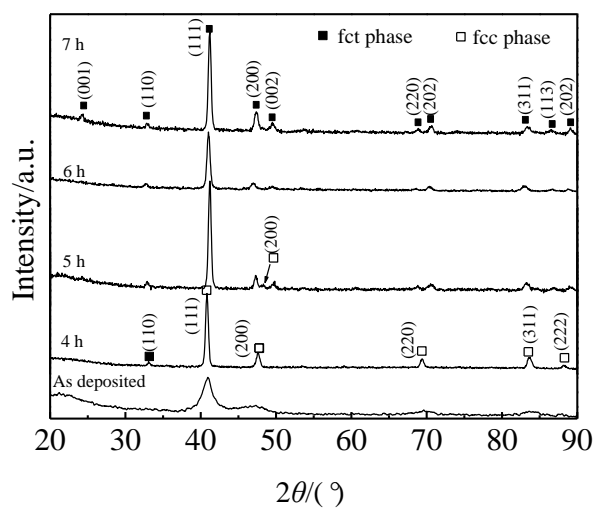

Fig.1 XRD patterns of FePd films $(d=90 \mathrm{~nm})$ annealed at $600^{\circ} \mathrm{C}$ for different time

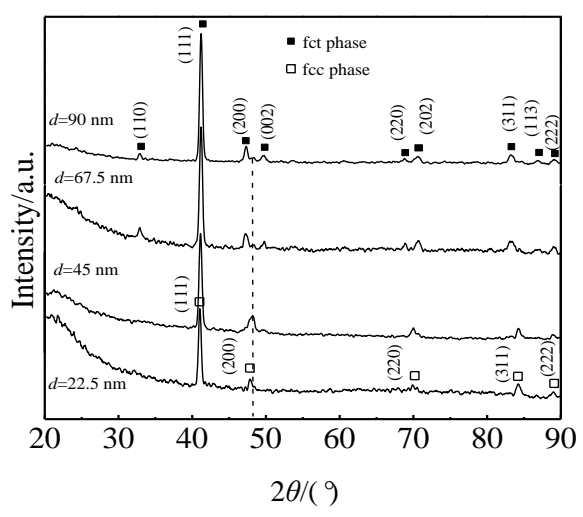

Fig.2 X-ray patterns of FePd films with different thickness annealed at $600{ }^{\circ} \mathrm{C}$ for $5 \mathrm{~h}$

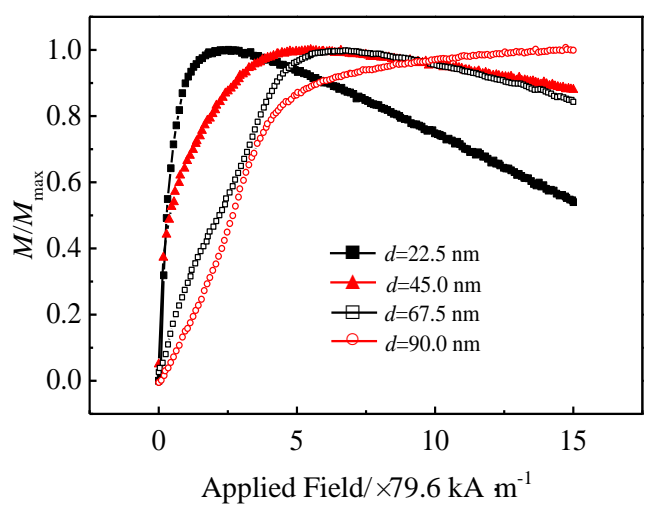

Fig.3 Initial magnetization curves of FePd films annealed at $600{ }^{\circ} \mathrm{C}$ for $5 \mathrm{~h}$ 


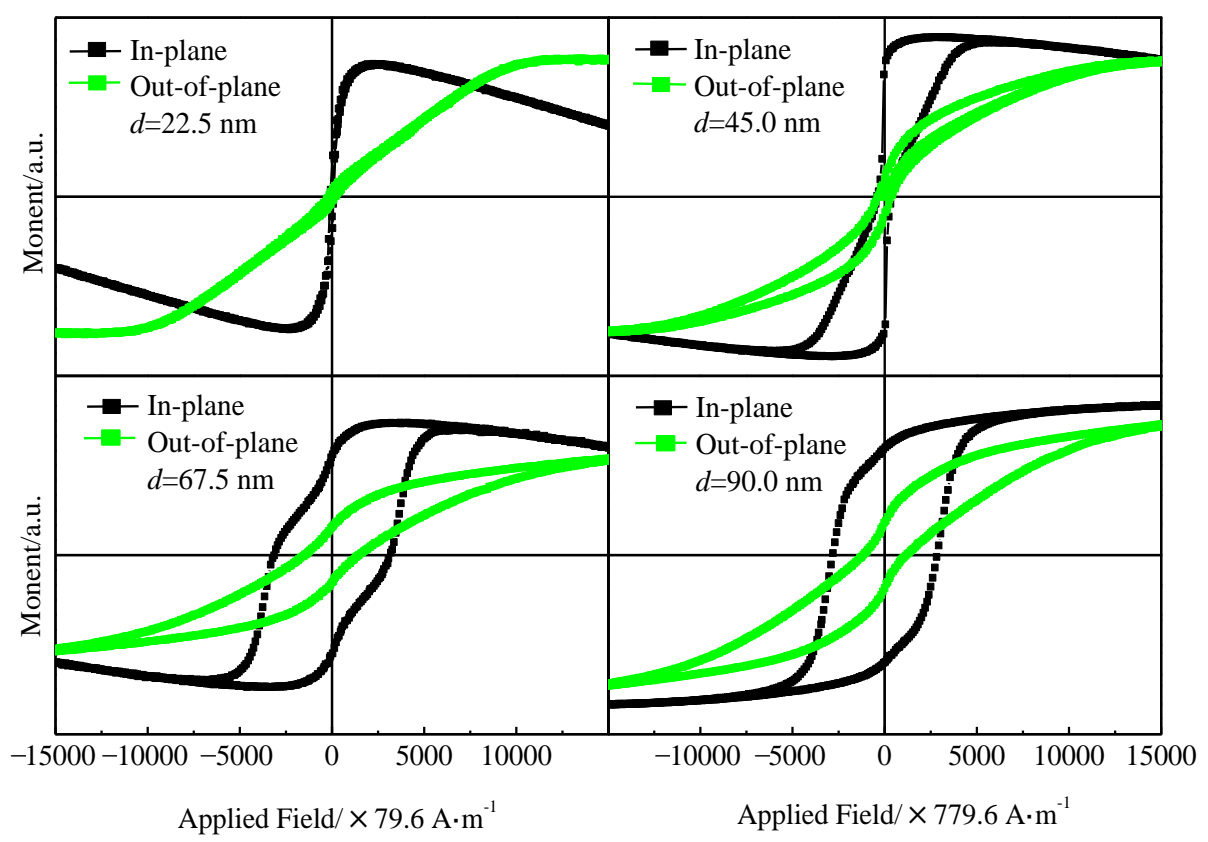

Fig.4 Out-of-plane and in-plane hysteresis loop for FePd alloy films annealed $600{ }^{\circ} \mathrm{C}$ for $5 \mathrm{~h}$

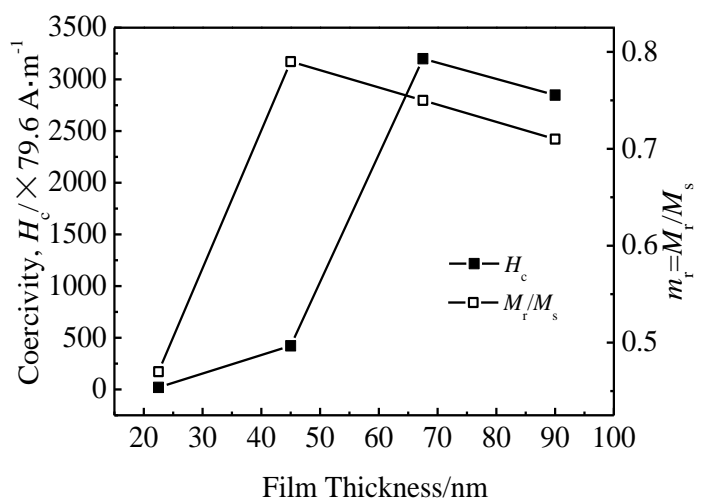

Fig.5 Coercivity and remanence ratio of FePd films annealed at $600{ }^{\circ} \mathrm{C}$ for $5 \mathrm{~h}$ as a function of film thickness

The higher remanence ratio shown here suggests that the magnetic particles in the FePd alloy film are exchangecoupled. A maximum value of $m_{\mathrm{r}}=0.79$ is obtained for $d=45$ nm. According to the model of Kneller and Hawig ${ }^{[11]}$, an appropriate grain size in the fct phase can enhance exchange-coupling. The $H_{\mathrm{c}}$ of films increases rapidly from 20 $\times 79.6 \mathrm{~A} / \mathrm{m}$ to $3.2 \times 79.6 \mathrm{kA} / \mathrm{m}$, and then the value is decreased to $2.8 \times 79.6 \mathrm{kA} / \mathrm{m}$. The relationship between coercivity and anisotropy constant can be expressed as:

$$
H_{\mathrm{c}}=K_{\mathrm{K}} / \mu_{0} M_{\mathrm{sm}}
$$

where $M_{\mathrm{sm}}$ is the saturation magnetization of soft magnetic phase and $K_{\mathrm{K}}$ is the anisotropy constant of the hard magnetic phase. The reduction in $H_{\mathrm{c}}$ with increasing film thickness is ascribed to excessive grain grown in the fct phase, an effect that has previously been reported by Kaneko et $\mathrm{al}^{[12]}$.

\section{Conclusions}

1) The occurrence of phase transformation from fcc to fct in thick films is easier than thin films.

2) The thickness of FePd alloy films strongly affects the microstructure and phase transformation process. When FePd alloy films are annealed at $600^{\circ} \mathrm{C}$ for $5 \mathrm{~h}$, the coereivity (with $d=67.5 \mathrm{~nm}$ ) and remanence ratio (with $d=45 \mathrm{~nm}$ ) could reach a maximum value of approximately $3.2 \times 79.6 \mathrm{kA} / \mathrm{m}$ and 0.79 , respectively.

\section{References}

1 Gehanno V, Marty A, Gilles B et al. Phys Rev B[J], 1997, 55(18): 12552

2 Gan'shina E, Guschin V, Romanov I et al. J MMM[J], 1999, 193: 174

3 Chen J S, Lim C, Ding Y F et al. J MMM[J], 2006, 303: 309

4 Marcin Perzanowshi, Yevhen Zabila, Michal Krupinski et al. $J$ Appl Phys[J], 2012, 111: 074301

5 Marcin Perzanowski, Michal Krupinski, Arkadiusz Zarzycki et al. Appl Surface Science.[J], 2014, 302: 129

6 Mitsuru Ohtake, Osamu Yabuhara, Kousuke Tobari et al. J Appl Phys[J], 2011, 109: 07B 757

7 Ichitsubo T, Takashima S, Matsubara E et al. Appl Phys Lett $[\mathrm{J}]$, 2010, 97: 182508

8 Barmak K, Kim J, Shell S et al. Appl Phys Lett [J], 2002, 80(22): 4268

9 Pecko D, Rozman K Z, McGuiness P J et al. J Appl Phys[J], 2010, 107: 09A712 
10 kohda M, Limori S, Ohsugi R et al. Appl Phys Lett[J], 2013, 102: 102411
11 Kneller E F, Hawig R. IEEE Tran Magn[J], 1991, 27: 3588

12 Kaneko H, Homma M, Suzuki K. Trans JIM[J], 1968, 9: 124

\title{
玻璃祄底上 FePd 薄膜的厚度对其结构和磁性能的影响
}

\author{
张艳丽 ${ }^{1,2}$, 成 钢 ${ }^{1,2}$, 许小宗 ${ }^{2}$, 潘 旷 $^{2}$, 李 林 $^{1,2}$, 杜玉松 ${ }^{1,2}$, 张 金金 $^{1,2}$, 马 垒 ${ }^{1,2}$, 顾正飞 ${ }^{1,2}$ \\ (1. 广西信息材料重点实验室, 广西 桂林 541004) \\ (2. 桂林电子科技大学, 广西 桂林 541004)
}

摘 要: 采用磁控溅射方法在玻璃祄底上制备了不同厚度的 FePd 合金薄膜。利用 X 射线衍射 (XRD), 能谱 (EDS) 和物理性能测试研究 了薄膜厚度对结构和磁性能的影响。结果表明, 在 FePd 合金薄膜中有序化过程发生在更厚的薄膜中。随着薄膜厚度从 $d=22.5 \mathrm{~nm}$ 增加 到 $d=67.5 \mathrm{~nm}$, 面内矫顽力刚开始急剧增大, 然后随着薄膜厚度的进一步增加矫顽力会减小。在 $d=67.5 \mathrm{~nm}$ 时面内矫顽力最大约为 $3.2 \times 79.6$ $\mathrm{kA} / \mathrm{m}$ 。

关键词: FePd 薄膜; 晶粒生长; 磁化过程

作者简介: 张艳丽, 女, 1979 年生, 硕士, 讲师, 桂林电子科技大学材料科学与工程学院, 广西 桂林 541004, 电话: 0773-2291434, E-mail: zhangyanli@guet.edu.cn 